\title{
Retracted: A Prospective Study of Early Loaded Single Implant-Retained Mandibular Overdentures: Preliminary One-Year Results
}

\section{International Journal of Dentistry}

Received 5 August 2013; Accepted 5 August 2013

Copyright (C) 2013 International Journal of Dentistry. This is an open access article distributed under the Creative Commons Attribution License, which permits unrestricted use, distribution, and reproduction in any medium, provided the original work is properly cited.

The paper titled "A Prospective Study of Early Loaded Single Implant-Retained Mandibular Overdentures: Preliminary One-Year Results" [1], published in International Journal of Dentistry, has been retracted as it is found to contain a substantial amount of material from the paper "A prospective study of immediately loaded single implant-retained mandibular overdentures: preliminary one-year results," Liddelow G. J., Henry P. J., Journal of Prosthetic Dentistry, vol. 97, no. 6, pp. S126-S137, 2007.

\section{References}

[1] A. M. El-Sheikh, O. F. Shihabuddin, and S. M. F. Ghoraba, "A prospective study of early loaded single implant-retained mandibular overdentures: preliminary one-year results," International Journal of Dentistry, vol. 2012, Article ID 236409, 2012. 


\title{
A Prospective Study of Early Loaded Single Implant-Retained Mandibular Overdentures: Preliminary One-Year Results
}

\author{
Ali M. El-Sheikh, ${ }^{1}$ Omar F. Shihabuddin, ${ }^{2}$ and Sahar M. F. Ghoraba ${ }^{3}$ \\ ${ }^{1}$ Department of Prosthetic Dentistry, Faculty of Dentistry, Tanta University, Tanta 31111, Egypt \\ ${ }^{2}$ Department of Oral Maxillofacial Surgery, Dammam Dental Centre, Dammam Medical Complex, Dammam 31433, Saudi Arabia \\ ${ }^{3}$ Department of Oral Medicine, Periodontology, Radiology and Diagnosis, Faculty of Dentistry, Tanta University, Tanta 31111, Egypt
}

Correspondence should be addressed to Ali M. El-Sheikh, aliel-sheikh@hotmail.com

Received 24 October 2011; Revised 17 December 2011; Accepted 3 January 2012

Academic Editor: Dimitris N. Tatakis

Copyright ( 2012 Ali M. El-Sheikh et al. This is an open access article distributed under the Creative Commons Attribution License, which permits unrestricted use, distribution, and reproduction in any medium, provided the original work is properly cited.

Purpose. To investigate the predictability of simplifying mandibular overdenture treatment using one-stage surgery and early prosthetic loading of a single implant. Materials and Methods. Twenty edentulous patients with problematic existing mandibular dentures were treated. A single implant with a chemically modified surface (SLActive, Straumann AG, Basel, Switzerland) was placed into the mandibular midline. The patients were recalled at 3, 6 and 12 months. Clinical assessments and marginal bone loss using standardized radiographs were recorded. All complications, failures and maintenance were noted. Visual analog-scale questionnaires were used to record patient satisfaction in five categories. ANOVA was used to determine differences between means of marginal bone loss and different categories of patient staisfaction $(P=0.05)$. Results. The 20 early loaded implants were all surviving at the 12-month recall. All implants showed less than $1 \mathrm{~mm}$ of marginal bone loss by the end of the 1 -year with a significant increase during the follow-up period. Few prosthetic problems were reported. Patient satisfaction was high with a significant increase in all comfort and functional parameters. Conclusions. These preliminary 1-year results indicate that early loading of a single chemically modified surface implant used to retain a mucosa-borne mandibular overdenture is a safe, reliable, and cost-effective treatment.

\section{Introduction}

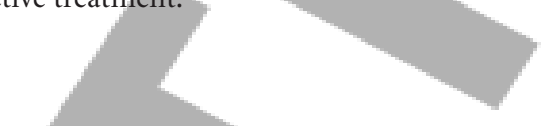

Rehabilitation of the completely edentulous mandible using implants to retain a fixed prosthesis is a predictable longterm treatment modality $[1,2]$. High implant success rates have been achieved by Engquist et al. [3] (99\%), Johns et al. [4] (96.2\%), and Bergendal and Engquist [5] (100\%), using 2 or more implants to anchor an overdenture. Two implantretained overdentures with separated implants have been reported with high implant success rates (97-100\%) and functional improvement [5-8]. There is consensus that $2 \mathrm{im}-$ plants splinted $[9-11]$ or unsplinted $[6,12,13]$ in the interforaminal region of the mandible are sufficient to support an overdenture [14, 15]. Indeed, the McGill consensus statement suggested that the 2 -implant overdenture should be the first choice of treatment for the edentulous mandible [16].

The success of the previous treatment modalities, while excellent, is unfortunately outside the financial scope of many compromised edentulous patients. A cost comparison study between an unsplinted 2-implant retained mandibular overdenture and a conventional complete mandibular denture showed the direct cost of the overdenture to be 2.4 times the cost of the complete denture [17]. It is, therefore, desirable for clinicians to be able to offer a significant functional improvement of the problematic mandibular complete denture in a cost effective manner. Concomitantly, a reduction in the overall time frame of clinical, technical, and maintenance procedures needed to achieve this goal would be advantageous [18].

Further directions with case reports and prospective studies point towards a more conservative approach: the use of only a single implant to support a mandibular overdenture [18-24]. Implant outcome and patient satisfaction has shown to be comparable whether one or two implants are used for support of mandibular overdentures [23, 24]. 
A chemically modified titanium surface, SLActive (Straumann AG, Basel, Switzerland), has been developed, using the well-documented topography of the sandblasted, large grit, acid-etched (SLA, Straumann AG) surface. The surface is chemically active, with high surface free energy, reduced atmospheric hydrocarbon contamination, and strong hydrophilicity; the water contact angle is $0^{\circ}$ compared with $139.9^{\circ}$ for the standard SLA surface $[25,26]$.

This surface showed enhanced bone formation and significantly increased cellular activity and proliferation of vascular structures compared with the conventional SLA surface in the first 14 days following implantation, as demonstrated by histological and immunohistochemical evaluation [27]. In vivo animal studies have demonstrated $60 \%$ greater boneformation at the SLActive surface compared with SLA, andthere is earlier formation of more mature bone [28]. Mean removal torque values were also found to be consistently higher in the first 8 weeks, corresponding to the early healing period [29]. This evidence suggests increased implant stability in the critical early osseointegrated period. Therefore, early loading protocol (3-4 weeks) using SLActive implants has become more accepted and more prevalent for situations ranging from single-tooth replacement to full-arch restorations $[30,31]$.

The purpose of this study was to investigate the predictability of simplifying mandibular overdenture treatment using one-stage surgery and early prosthetic loading of a single chemically modified titanium surface (SLActive) implant.

\section{Materials and Methods}

2.1. Patient Selection. Twenty completely edentulous subjects, 12 men and 8 women, ranging from 52 to 70 years of age (mean age 62 years) were included in the study. These patients were treated in Dammam Dental Centre, Dammam Medical Complex (Dammam, Saudi Arabia) in the period from January to April 2010. All patients signed an informed consent form. Ethical approval for the project was granted by the Human Research Ethics Committee of The Dammam Medical Complex, Dammam, Saudi Arabia. The primary complaints among the patients referred to the clinic for treatment were related to poor retention of the mandibular denture, instability, denture sores, and phonetic problems.

Inclusion criteria dictated that the patient is completely edentulous for at least 2 years, has a maladaptive mandibular denture, and has sufficient bone for an implant of at least $10 \mathrm{~mm}$ length and $4.1 \mathrm{~mm}$ diameter. Exclusion criteria included any medical condition contraindicating implant surgery, logistic or physical reasons that could affect followup, psychiatric problems, and disorders to the implant site related to a history of radiation therapy to the head and neck, or bone augmentation.

2.2. Surgical Procedures. Thorough clinical evaluation of the proposed implant placement site was carried out. Preoperative panoramic, conventional lateral cephalometric, and periapical radiographs were used for radiographic evaluation of the placement site to avoid potential complications with important anatomy in this region.

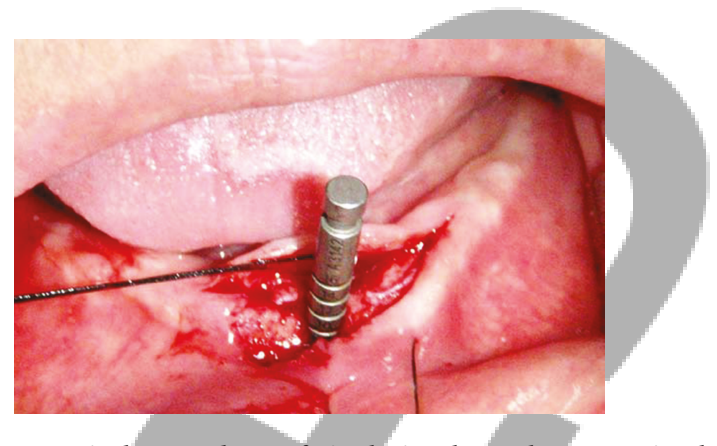

FIgUre 1: Surgical procedure of single implant placement in the mandibular midline.

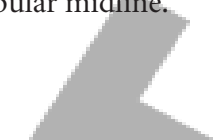

The components used were regular platform soft tissue level implants (SLActive, Straumann AG, Basel, Switzerland) with a diameter of $4.1 \mathrm{~mm}$. The Straumann $3.4 \mathrm{~mm}$ height retentive anchor with a titanium matrix provided the prosthetic anchorage. All patients were provided with a single implant of at least $10 \mathrm{~mm}$ in length inserted in the mandibular midline. Twelve patients were provided with $10 \mathrm{~mm}$ long implants while the remaining eight patients were provided with $12 \mathrm{~mm}$ long implants.

Bilateral mental nerve blocks and local infiltration in the labial and lingual sulcus were administered with lignocaine $2 \%$. One-stage surgical approach was followed throughout the whole study (Figure 1). A minimal crestal incision (envelope type) was made, and a mucoperiosteal flap was raised, on both the labial and the lingual aspects, to enable adequate visualization of the lingual aspect of the mandible and to evenly divide the available keratinized tissue. This enabled the abutment to be surrounded by attached gingiva. The osteotomy was prepared using a standard bone drilling protocol, according to the manufacturer's directions with extreme care to avoid penetration of the lingual or inferior cortex. Bone quality was identified, and bone tap was used in types 1 and 2. Initial implant stability was tested manually by hand and insertion torques $\geq 35 \mathrm{Ncm}$ were acceptable. Healing abutments of appropriate length were connected, and the mucosa was adjusted and sutured (4-0 Vicryl, Ethicon, Johnson \& Johnson, Brussels, Belgium).

Any patients with implants lacking primary stability at this stage were excluded from further participation in the study and replaced; this was not considered an implant or treatment failure. Any patients with inadequate bone at the time of surgery were also excluded from further participation in the study. Patients excluded for these reasons were offered implantation using the conventional delayed loading protocol or another form of treatment.

Antibiotic (Augmentin $625 \mathrm{mg}$ ) and nonsteroidal antiinflammatory (Ibuprofen $400 \mathrm{mg}$ ) medications were given to the patients every 8 hours for 5 days postoperatively. Immediately after surgery, the mandibular denture of each participant was modified and relined with a soft tissue conditioner (Viscogel, Dentsply, Konstanz, Germany). All patients were limited to a soft diet for 10 days and instructed to leave the denture out at night. The patients were instructed in 


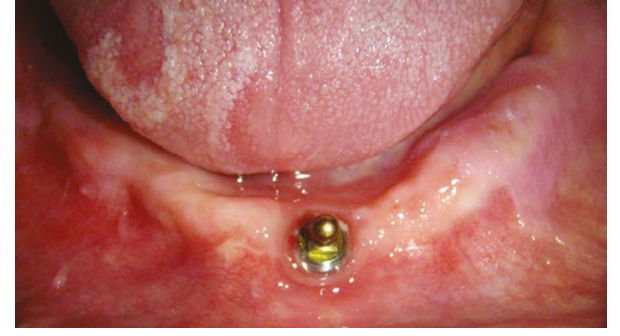

FIGURE 2: Retentive anchor screwed into the implant 3 weeks after implant placement.

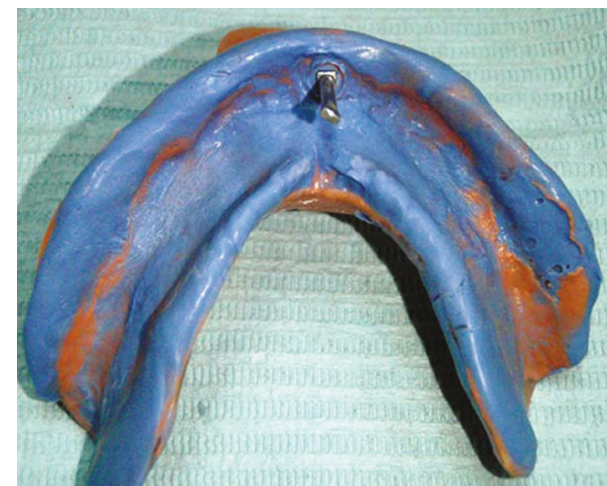

FIgURE 3: Transfer pin positioned in the impression before pouring.

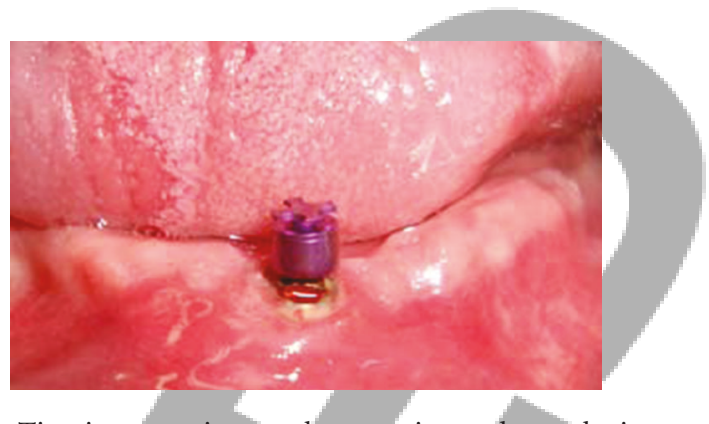

FIGURE 4: Titanium matrix over the retentive anchor to be incorporated in the finished denture.

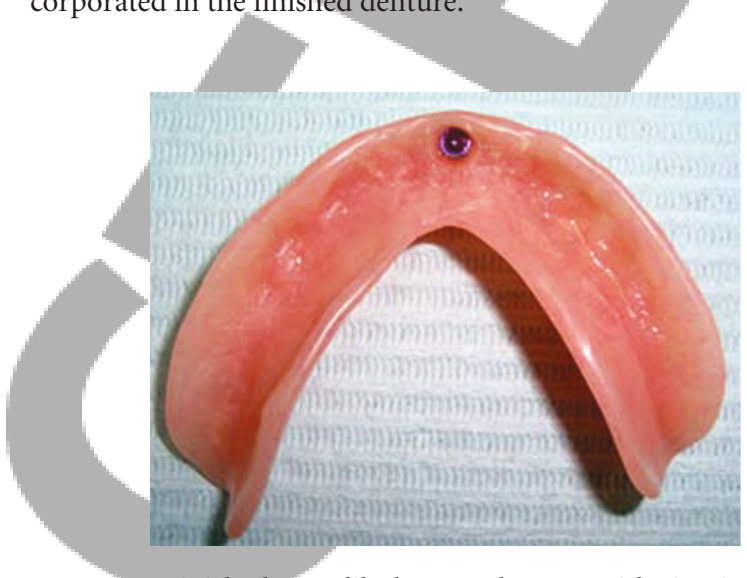

FIGURE 5: Finished mandibular overdenture with titanium matrix immediately before insertion. a plaque control protocol at the time of implant placement and this was reinforced at subsequent reviews.

\subsection{Prosthetic Procedures. Three weeks after implant place-} ment, the healing abutment was removed and the retentive anchor was screwed to the implant (Figure 2). A torque of $35 \mathrm{Ncm}$ was used for tightening the retentive anchor. Preliminary impressions for upper and lower arches were taken with stock trays using irreversible hydrocolloid (Hydrogum, Zhermack, Italy). The impression for the lower arch was taken directly over the retentive anchor. Secondary impressions were taken with autopolymerized acrylic resin special trays using vinyl polysiloxane impression material (Express, 3 M ESPE Dental Products, USA). The transfer pin was positioned in the lower impression before pouring it (Figure 3). Record blocks were fabricated on the duplicates of the master models for jaw registration. Teeth try-in and manufacturing of the acrylic dentures were carried out using standard prosthetic procedures. The titanium matrix (Figure 4) was incorporated in the final prosthesis using the direct technique inside the patient's mouth. Fabrication of the prostheses was finished in 1 week. Therefore, the maxillary complete denture and implant-retained mandibular overdenture (Figure 5) were delivered to the participants approximately 4 weeks after implant placement.

2.4. Radiographic Analysis. Standardized intraoral radiographs using a long cone technique of the implant were obtained. To provide a geometrically reproducible alignment, an index was recorded for each patient on the inserted mandibular overdenture with the use of vinyl siloxane material. With the aid of Hawe's sensor holder system (Kerr, KerrHawe SA, Switzerland), the radiographs were taken using direct digital imaging system (Trophy RVG, William Green Pty Ltd., Australia). Images were displayed on a computer screen with such a dimension and brightness that the observer could read comfortable and accurately the image. On each image, the implant-retentive anchor interface and first bone-to-implant contact were identified and marked with a cursor on the mesial and distal sides of the implant. The analysis program calculated and reported the distance between the two points with a degree of accuracy of $\pm 0.01 \mathrm{~mm}$. The same procedure was performed with all follow-up radiographs. The initial postoperative radiographs immediately after insertion of the new/final overdentures (baseline radiography) were compared with the follow-up radiographs 3, 6, and 12 months of functional loading. The vertical bone loss was calculated by subtracting the bone heights in the baseline radiographs from those of follow-up radiographs. Data were collected blindly by one experienced observer throughout the entire study.

2.5. Patient Satisfaction. Self-administered questionnaires that followed the Visual Analogue Scale (VAS) method were completed by patients preoperatively and at each scheduled recall to assess oral comfort and function [32]. Each VAS questionnaire consisted of a $100 \mathrm{~mm}$ line anchored at the beginning and end by opposing responses/statements such as "not at all satisfied" to "totally satisfied". The participants 


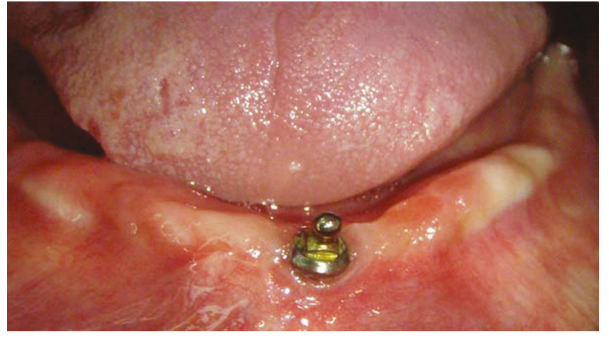

Figure 6: Acceptable soft tissue health with no mucosal enlargement around the retentive anchor at 12 -month recall.

marked a vertical line on the horizontal VAS line to indicate their feeling. Scores were determined by measuring the distance (in $\mathrm{mm}$ ) from the left starting point of the line to the intersection of the response line. There were 10 questions, in 5 categories: general satisfaction (not at all satisfied, totally satisfied), social life (not at all improved the social life, totally improved the social life), mastication of hard food (not at all improved mastication of hard food, totally improved mastication of hard food), comfort (not at all comfort, totally comfort), and fit (not at all fit, totally fit).

2.6. Data Collection. The data collection (clinical and radiographic outcomes) of all patients was performed as follows: at the completion of the prosthetic treatment (baseline) and after 3,6 , and 12 months of functional loading.

2.7. Statistical Analysis. The measurements for the marginal bone loss were carried out on the mesial and distal surface for each implant and the mean was taken. The difference between the values at the baseline and the follow-up recall visits was based on the average bone loss yalue for each implant. The data were statistically analyzed using one-way repeated measures ANOVA followed by Tukey's test at 95\% confidence level (SPSS for Windows, version 10.0, SPSS Incorporated, Chicago, IL, USA).

\section{Results}

Three patients were excluded from the study during the surgical placement of the implants. Two patients were excluded due to lack of primary stability and one due to inadequate bone. The 20 early loaded implants were all surviving at the 12-month recall. Prosthetic problems were relatively few with attachment functioning well at the 1-year recall and reline unnecessary. Two patients required the spring of the titanium matrix to be replaced with a new one due to loss of the retention approximately 9 months after functional loading. Plaque control was considered acceptable for most patients and considered relatively simple by the patients themselves. Calculus formation that impeded seating of the titanium matrix was encountered on 2 occasions and was further prevented by more diligent hygiene. Soft tissue health was visually assessed and was acceptable in all patients with no evidence of mucosal enlargement at recall appointments, as shown in Figure 6 (12-month follow-up).
TABle 1: Comfort and functional parameters (Means and SDs in $\mathrm{mm})$ at pretreatment and all recall examinations.

\begin{tabular}{lcccc}
\hline & Pretreatment & 3 months & 6 months & 12 months \\
\hline $\begin{array}{l}\text { General } \\
\text { satisfaction }\end{array}$ & $19.15(2.41)$ & $77.05(3.85)$ & $85.85(3.31)$ & $91.50(1.70)$ \\
$\begin{array}{l}\text { Social life } \\
\text { Mastication }\end{array}$ & $30.70(1.75)$ & $76.30(2.47)$ & $81.3(3.26)$ & $89.95(2.04)$ \\
of hard food & $19.70(2.00)$ & $75.65(2.01)$ & $86.00(2.03)$ & $90.15(1.46)$ \\
Comfort & $20.90(1.65)$ & $67.80(2.35)$ & $79.10(1.80)$ & $82.85(3.23)$ \\
Fit & $21.60(1.93)$ & $87.40(2.21)$ & $92.60(1.64)$ & $95.50(1.28)$ \\
\hline
\end{tabular}

All implants showed less than $1 \mathrm{~mm}$ of marginal bone loss by the end of the 1-year follow-up period. The mean vertical bone loss from baseline to 3 months was $0.30 \mathrm{~mm}$ $(\mathrm{SD}=0.06)$. The mean vertical bone loss from baseline to 6 months was $0.63 \mathrm{~mm}(\mathrm{SD}=0.07)$. The mean vertical bone loss from baseline to 12 months was $0.93 \mathrm{~mm}(\mathrm{SD}=0.06)$. The comparison of the mean values of bone loss from 3 to 6 months, from 3 to 12 months, and from 6 to 12 months was statistically significant $(P<0.001)$.

The mean values and standard deviations (in $\mathrm{mm}$ ) of comfort and functional parameters in the VAS questionnaires filled by all patients at pretreatment and all recall appointments were summarized in Table 1. Statistical analysis of these data showed a significant improvement in all parameters of oral comfort and prosthesis function $(P<0.001)$. Direct questioning indicated that common pretreatment problems, such as recurrent denture ulceration, had been eliminated and nonmasticatory functions such as yawning and laughing could be accomplished without complications.

\section{Discussion}

The conventional loading protocols for dental implants allow for a period of undisturbed healing after implant placement, to minimize the risk of healing and osseointegration complications. In recent years, shorter restoration times have become more common, especially due to increasing patient demands.

The purpose of this prospective study was to ascertain whether simplifying mandibular overdenture treatment using one-stage surgery and early prosthetic loading of a single implant would achieve acceptable implant success rates and provide the functional improvement expected using conventional techniques. While the study may be of limited duration, it provides sound support for the hypothesis that the single-implant mandibular overdenture can provide improved retention, stability, masticatory performance, and confidence for the maladaptive complete denture wearers. The limitations of the small sample size of 20 participants and the short follow-up period of 1 year need to be acknowledged, and the findings presented, therefore, must be interpreted cautiously.

Presurgical evaluation of the patient was simplified by using the relatively inexpensive panoramic, lateral cephalometric, and periapical radiographs. These important diagnostic aids, together with adequate visualization of the lingual surface of the bony ridge after flap evaluation, 
cannot be overstated in light of reports of life-threatening hemorrhage from the floor of the mouth during routine implant placement in this region $[33,34]$. The present study on the early functioning single-implant overdenture showed excellent survival rates (100\%) and dramatically improved patient-reported satisfaction levels in patients with pretreatment denture problems. These results are in agreement with the study by Alsabeeha et al. [30] which reported $100 \%$ of early loading for the Southern wide and Neoss regular implants. With respects to the $100 \%$ survival reported, the possibility that the authors are skilled clinicians experienced with this technique should be considered, so the single-implant procedure cannot be generalized to the entire practicing community. However, the procedures involved are not complex, provided that the mentioned protocol is followed. It is difficult to postulate whether two implants are twice as effective as one or even whether there is any discernable difference from a patient perspective.

In general, implant overdentures have a less controlled loading when compared to fixed prostheses [35]. It may be postulated that forces, both axial and lateral, generated by an overdenture on a single implant have the potential to be greater than those produced by a multiple implant-retained overdenture. Maeda et al. [36] examined the biomechanical rationale of a single implant-retained mandibular overdenture using an in vitro model. The model revealed statistically significantly smaller lateral forces to the ball abutments for single-compared to two-implant overdentures with molar loading. A higher load was observed when the denture was loaded in the midline region. No significant difference in three-dimensional denture base movement was observed between single- and two-implant overdentures in the midline and molar regions. They concluded that, overall, the singleimplant overdenture had similar biomechanical effects to a two-implant overdenture in terms of lateral forces to the abutment and denture base movements under molar functional loads. However, the authors did stress the in vitro nature of the model and the need for follow-up studies performed in a clinical setting.

Prosthetic problems were relatively few compared to other studies $[14,15]$, with attachment functioning well at the 1-year recall and relines unnecessary. This is in agreement with the study by Liddelow and Henry [18] in which plastic caps and rubber O-rings were used. The present study used the titanium matrix with the spring. The inherent resilience with these kinds of attachments (i.e., plastic caps and rubber O-rings, and titanium matrix and spring) may allow more movement and, therefore, less strain and potential for wear. The other studies $[14,15]$ used metal retentive caps which may explain the occurrence of more prosthetic problems in these studies. The titanium matrix is, however, substantially small, resulting in an enough amount of denture base around the attachment. Therefore, no fracture of the denture bases at the attachment site was recorded in all cases. A denture with this type of attachment is primarily tissue borne and implant retained. From a prosthodontic perspective, if the implant is not placed in the ideal position, an unfavorable overbulking of the denture base would result.
Plaque control was considered acceptable for most patients and considered relatively simple by the patients themselves. Soft tissue health was acceptable in all patients with no evidence of mucosal enlargement at all recall appointments. The findings in the present study are in agreement with the studies of Liddelow and Henry [18] and Cordioli et al. [19], which also reported no mucosal enlargement during the follow-up period. Mucosal enlargement has been reported in other studies such as that by Engquist et al. [3], which had an incidence of $25 \%$, and that by Wright et al. [11], which reported $35 \%$.

The overall mean marginal bone loss after 1 year of function in the present study was less than $1 \mathrm{~mm}$ which is in agreement with previous studies [18-21]. The comparison of the mean values of bone loss from 3 to 6 months, from 3 to 12 months, and from 6 to 12 months was statistically significant. The explanation for that could be the presence of only one implant in the mandible which might have been subjected to excessive forces.

The cost of treatment for edentulous patients is a significant determinant of treatment acceptance, compared to other groups of patients. Any reduction in cost to the patient becomes more critical. The study measuring the cost of implant overdenture therapy has been done with a microcosting technique, which examines the direct cost to the patient and, also, indirect costs, such as time and transportation [17]. Measured in this way, the difference in cost between 1 and 2 implants would be primarily half the component costs, as the time differential from both the surgical and prosthodontics viewpoint would be minimal. The few prosthetic problems reported during the 1-year follow-up period are interesting from a maintenance cost standpoint. If this type of overdenture design and attachment component has a lower maintenance requirement, then this has favorable implications with respect to cost-effectiveness.

The preliminary 1-year report on this procedure indicates that it is a positive treatment modality, which could make it possible for completely edentulous patients with limited resources to benefit from an implant-retained prosthesis. It may well be considered to be the entry level treatment option for rehabilitation of the edentulous mandible in selected patients, especially the underprivileged geriatric groups. A limitation of this study is the lack of a comparison group with the more conventional 2-implant overdenture. Given the clear improvements and reduced costs with this modality, serious consideration for longer term and more extensive clinical trials is warranted. In long term, with favorable results, the McGill consensus statement may be challenged.

\section{Conclusions}

Within the limitation of this study and the preliminary nature of this 1-year report, it may be concluded that the early loaded, single implant-retained mandibular overdenture, using a chemically modified surface implant (SLActive), is an alternative treatment proposition for selected patients. The relatively simple treatment protocol and reduced component and laboratory involvement mean that a greater number 
of edentulous patients could benefit from this protocol. These preliminary findings must be confirmed by long-term randomized controlled clinical trials with a larger sample size and comparison groups (i.e., one versus two implants).

\section{References}

[1] R. Adell, U. Lekholm, B. Rockler, and P. I. Brånemark, "A 15year study of osseointegrated implants in the treatment of the edentulous jaw," International Journal of Oral Surgery, vol. 10, no. 6, pp. 387-416, 1981.

[2] A. Petersson, B. Rangert, K. Randow, and I. Ericsson, "Marginal bone resorption at different treatment concepts using Brånemark dental implants in anterior mandibles," Clinical Implant Dentistry and Related Research, vol. 3, no. 3, pp. 142$147,2001$.

[3] B. Engquist, T. Bergendal, T. Kallus, and U. Linden, "A retrospective multicenter evaluation of osseointegrated implants supporting overdentures," The International Journal of Oral \& Maxillofacial Implants, vol. 3, no. 2, pp. 129-134, 1988.

[4] R. B. Johns, T. Jemt, M. R. Heath et al., "A multicenter study of overdentures supported by Brånemark implants," The International Journal of Oral \& Maxillofacial Implants, vol. 7, no. 4, pp. 513-522, 1992.

[5] T. Bergendal and B. Engquist, "Implant-supported overdentures: a longitudinal prospective study," The International Journal of Oral \& Maxillofacial Implants, vol. 13, no. 2, pp. 253262, 1998.

[6] K. Gotfredsen and B. Holm, "Implant-supported mandibular overdentures retained with ball or bar attachments: a randomized prospective 5-year study," The International Journal of Prosthodontics, vol. 13, no. 2, pp. 125-130, 2000.

[7] J. S. Feine, P. de Grandmont, P. Boudrias et al., "Within-subject comparisons of implant-supported mandibular prostheses: choice of prosthesis," Journal of Dental Research, vol. 73, no. 5, pp. 1105-1111, 1994.

[8] O. Donatsky, "Osseointegrated dental implants with ball attachments supporting overdentures in patients with mandibular alveolar ridge atrophy," The International Journal of Oral \& Maxillofacial Implants, vol. 8, no. 2, pp. 162-166, 1993.

[9] R. Mericske-Stern and G. A. Zarb, "Overdentures: an alternative implant methodology for edentulous patients," The International Journal of Prosthodontics, vol. 6, no. 2, pp. 203-208, 1993.

[10] T. Jemt, J. Chai, J. Harnett et al., "A 5-year prospective multicenter follow-up report on overdentures supported by osseointegrated implants," The International Journal of Oral \& Maxillofacial Implants, vol. 11, no. 3, pp. 291-298, 1996.

[11] P. S. Wright, R. M. Watson, and M. R. Heath, "The effects of prefabricated bar design on the success of overdentures stabilized by implants," The International Journal of Oral \& Maxillofacial Implants, vol. 10, no. 1, pp. 79-87, 1995.

[12] I. Naert, M. Quirynen, G. Theuniers, and D. van Steenberghe, "Prosthetic aspects of osseointegrated fixtures supporting overdentures. A 4-year report," The Journal of Prosthetic Dentistry, vol. 65, no. 5, pp. 671-680, 1991.

[13] A. G. Payne, A. Tawse-Smith, R. Kumara, and W. M. Thomson, "One-year prospective evaluation of the early loading of unsplinted conical Brånemark fixtures with mandibular overdentures immediately following surgery," Clinical Implant Dentistry and Related Research, vol. 3, no. 1, pp. 9-19, 2001.

[14] R. Mericske-Stern, "Clinical evaluation of overdenture restorations supported by osseointegrated titanium implants: a retrospective study," The International Journal of Oral \& Maxillofacial Implants, vol. 5, no. 4, pp. 375-383, 1990.

[15] J. N. Walton, M. I. MacEntee, and N. Glick, "One-year prosthetic outcomes with implant overdentures: a randomized clinical trial," The International Journal of Oral \& Maxillofacial Implants, vol. 17, no. 3, pp. 391-398, 2002.

[16] J. S. Feine, G. E. Carlsson, M. A. Awad et al., "The McGill consensus statement on overdentures. Mandibular two-implant overdentures as first choice standard of care for edentulous patients. Montreal, Quebec, May 24-25, 2002," The International Journal of Oral \& Maxillofacial Implants, vol. 17, no. 4, pp. 601-602, 2002.

[17] Y. Takanashi, J. R. Penrod, J. P. Lund, and J. S. Feine, "A cost comparison of mandibular two-implant overdenture and conventional denture treatment," The International Journal of Prosthodontics, vol. 17, no. 2, pp. 181-186, 2004.

[18] G. J. Liddelow and P. J. Henry, "A prospective study of immediately loaded single implant-retained mandibular overdentures: preliminary one-year results," Journal of Prosthetic Dentistry, vol. 97, no. 6, pp. S126-S137, 2007.

[19] G. Cordioli, Z. Majzoub, and S. Castagna, "Mandibular overdentures anchored to single implants: a five-year prospective study," Journal of Prosthetic Dentistry, vol. 78, no. 2, pp. 159$165,1997$.

[20] G. Krennmair and C. Ulm, "The symphyseal single-tooth implant for anchorage of a mandibular complete denture in geriatric patients," The International Journal of Oral \& Maxillofacial Implants, vol. 16, no. 1, pp. 98-104, 2001.

[21] G. Liddelow and P. Henry, "The immediately loaded single implant-retained mandibular overdenture: a 36-month prospective study," The International Journal of Prosthodontics, vol. 23, no. 1, pp. 13-21, 2010.

[22] N. Alsabeeha, A. G. T. Payne, R. K. De Silva, and M. V. Swain, "Mandibular single-implant overdentures: a review with surgical and prosthodontic perspectives of a novel approach," Clinical Oral Implants Research, vol. 20, no. 4, pp. 356-365, 2009.

[23] J. N. Walton, N. Glick, and M. I. Macentee, "A randomized clinical trial comparing patient satisfaction and prosthetic outcomes with mandibular overdentures retained by one or two implants," The International Journal of Prosthodontics, vol. 22, no. 4, pp. 331-339, 2009.

[24] M. Kronstrom, B. Davis, R. Loney, J. Gerrow, and L. Hollender, "A prospective randomized study on the immediate loading of mandibular overdentures supported by one or two implants: a 12-month follow-up report," The International Journal of Oral \& Maxillofacial Implants, vol. 25, no. 1, pp. 181-188, 2010.

[25] G. Zhao, Z. Schwartz, M. Wieland et al., "High surface energy enhances cell response to titanium substrate microstructure," Journal of Biomedical Materials Research-Part A, vol. 74, no. 1, pp. 49-58, 2005.

[26] F. Rupp, L. Scheideier, N. Olshanska, M. De Wild, M. Wieland, and J. Geis-Gerstorfer, "Enhancing surface free energy and hydrophilicity through chemical modification of microstructured titanium implant surfaces," Journal of Biomedical Materials Research-Part A, vol. 76, no. 2, pp. 323-334, 2006.

[27] F. Schwarz, M. Herten, M. Sager, M. Wieland, M. Dard, and J. Becker, "Histological and immunohistochemical analysis of initial and early osseous integration at chemically modified and conventional SLA ${ }^{\circledR}$ titanium implants: preliminary results of a pilot study in dogs," Clinical Oral Implants Research, vol. 18, no. 4, pp. 481-488, 2007. 
[28] D. Buser, N. Broggini, M. Wieland et al., "Enhanced bone apposition to a chemically modified SLA titanium surface," Journal of Dental Research, vol. 83, no. 7, pp. 529-533, 2004.

[29] S. J. Ferguson, N. Broggini, M. Wieland et al., "Biomechanical evaluation of the interfacial strength of a chemically modified sandblasted and acid-etched titanium surface," Journal of Biomedical Materials Research —Part A, vol. 78, no. 2, pp. 291297, 2006.

[30] N. H. M. Alsabeeha, A. G. T. Payne, R. K. De Silva, and W. M. Thomson, "Mandibular single-implant overdentures: preliminary results of a randomised-control trial on early loading with different implant diameters and attachment systems," Clinical Oral Implants Research, vol. 22, no. 3, pp. 330-337, 2011.

[31] A. Zöllner, J. Ganeles, J. Korostoff, F. Guerra, T. Krafft, and U. Brägger, "Immediate and early non-occlusal loading of Straumann implants with a chemically modified surface (SLActive) in the posterior mandible and maxilla: interim results from a prospective multicenter randomized-controlled study," Clinical Oral Implants Research, vol. 19, no. 5, pp. $442-$ 450, 2008.

[32] P. de Grandmont, J. S. Feine, R. Taché et al., "Within-subject comparisons of implant-supported mandibular prostheses: psychometric evaluation," Journal of Dental Research, vol. 73, no. 5, pp. 1096-1104, 1994.

[33] A. Mordenfeld, L. Andersson, and B. Bergström, "Hemorrhage in the floor of the mouth during implant placement in the edentulous mandible: a case report," The International Journal of Oral \& Maxillofacial Implants, vol. 12, no. 4, pp. 558-561, 1997.

[34] C. D. R. Kalpidis and R. M. Setayesh, "Hemorrhaging associated with endosseous implant placement in the anterior mandible: a review of the literature," Journal of Periodontology, vol. 75, no. 5, pp. 631-645, 2004.

[35] P.-I. Brånemark, "Possibilities and limitations in the clinical aspects of osseointegration," in Overdentures on Oral Implants. Proceedings of the Symposium on Implant Supported Overdentures, E. Schepers, Ed., pp. 11-13, Leuven University Press, Leuven, Belgium, 1991.

[36] Y. Maeda, M. Horisaka, and K. Yagi, "Biomechanical rationale for a single implant-retained mandibular overdenture: an in vitro study," Clinical Oral Implants Research, vol. 19, no. 3, pp. 271-275, 2008.

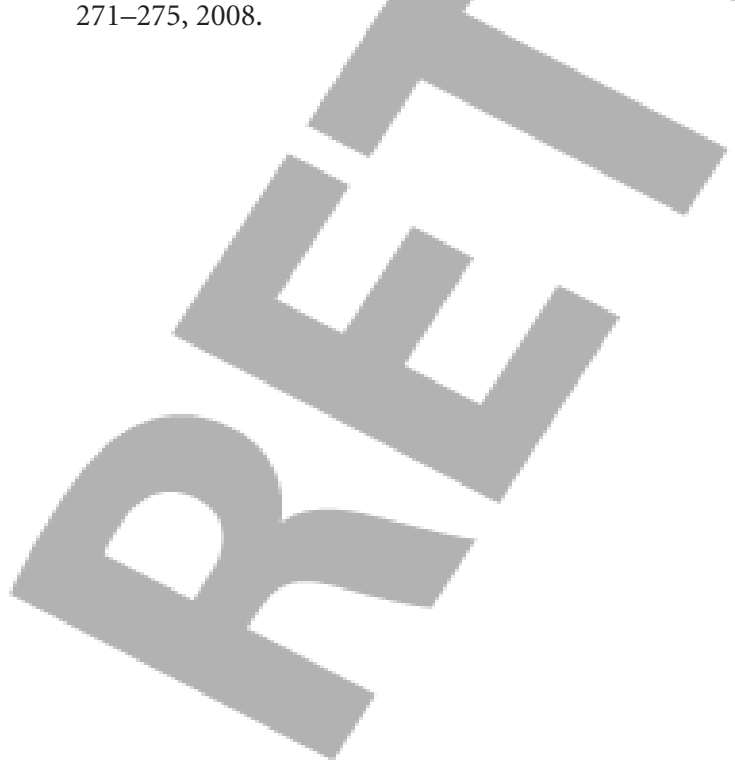

